\title{
miR-99b promotes metastasis of hepatocellular carcinoma through inhibition of claudin 11 expression and may serve as a prognostic marker
}

\author{
JIANHUI YANG, XIWU LIU, XIAOHUA YUAN and ZHIMING WANG \\ Department of General Surgery, Xiangya Hospital, Central South University, Changsha, Hunan 410008, P.R. China
}

Received April 22, 2015; Accepted May 18, 2015

DOI: $10.3892 /$ or.2015.4104

\begin{abstract}
Hepatocellular carcinoma (HCC) is a leading cause of cancer-related death worldwide, mainly due to its high rates of postoperative recurrence and metastasis. Moreover, there is no widely accepted prognostic marker of recurrence. Therefore, the aim of the present study was to determine whether such a marker could be provided by a microRNA (miRNA), since recent evidence indicates that miRNAs are important contributors to the metastatic phenotype. In the present study, we showed that miR-99b was expressed at high levels in tissues of patients with HCC and in cell lines derived from HCCs. Elevated levels of miR-99b predicted poor overall survival as well as disease-free survival of patients with HCC. Moreover, miR-99b expression levels correlated with capsule formation and microvascular invasion, which are required for postoperative recurrence. Overexpression or knockdown of miR-99b expression increased or inhibited, respectively, the metastasis of HCC cells in vitro. Furthermore, using a dual-luciferase assay, we demonstrated that miR-99b inhibited the expression of claudin 11 (CLDN11), a component of tight junction strands by directly targeting the 3'-untranslated region of CLDN11 mRNA. In addition, CLDN11 expression was increased or decreased when miR-99b expression was inhibited or elevated in the HCC cells, respectively. Moreover, the expression of miR-99b was inversely correlated with CLDN11 mRNA or CLDN11 levels in the HCC tissues. These findings suggest that a high level of miR-99b expression is an independent prognostic factor and correlates with poor survival of patients with HCC. Therefore, inhibition of miR-99b expression may serve as a therapeutic approach for inhibiting the metastatic phenotype of HCC.
\end{abstract}

Correspondence to: Dr Zhiming Wang, Department of General Surgery, Xiangya Hospital, Central South University, 87 Xiangya Road, Changsha, Hunan 410008, P.R. China

E-mail:wzmxycsu@hotmail.com

Key words: miR-99b, hepatocellular carcinoma, metastasis, claudin 11, prognosis

\section{Introduction}

Hepatocellular carcinoma (HCC) is the fifth most common malignant disease worldwide and is the second leading cause of cancer-related deaths ( 700,000 annually) (1-3). Although some patients will benefit from surgery (4), the long-term survival of most is unsatisfactory due to the high incidence of postoperative recurrence and metastasis (5). Unfortunately, effective measures to predict or prevent recurrence and metastasis of HCC are unavailable, mainly since the detailed mechanisms of postoperative metastasis and relapse remain to be determined.

Due to the absence of widely accepted nucleic acid and protein markers for predicting the prognosis of HCC, we focused our research on microRNAs (miRNAs), which are highly conserved RNAs, comprised of 19-22 nucleotides. miRNAs inhibit gene expression at the posttranscriptional level by binding to the 3' untranslated region (3'UTR) of target mRNAs (6). Different miRNAs are involved in the regulation of diverse physiological processes or contribute to pathological processes. Among these miRNAs, more than $50 \%$ are encoded by cancer-associated genomic regions or fragile sites (7), indicating that dysregulation of miRNA expression plays important roles in oncogenesis.

The epithelial-mesenchymal transition (EMT), which is implicated in pathologies such as organ fibrosis, tumor progression and metastasis $(8,9)$, is an important step in HCC metastasis (10). Among numerous miRNAs, miR-99b, which is encoded by chromosome 19, has attracted our research interest, since it promotes the EMT of normal murine mammary gland cells and increases their ability to migrate (11). Moreover, the expression of miR-99b is upregulated significantly in tumors such as multiple myeloma $(12,13)$ and esophageal cancer (14) and is associated with lymph node metastasis (15). These findings led us to propose the hypothesis that miR-99b functions as an oncogene and contributes to the metastatic phenotype of $\mathrm{HCC}$, although we are unaware of any studies indicating a role of miR-99b in HCC.

To test this hypothesis, we conducted experiments to detect the expression of miR-99b in HCC samples. We uncovered compelling evidence that miR-99b may serve as a prognostic marker for overall survival (OS) and disease-free survival (DFS) of patients with HCC. We analyzed the role of miR-99b in promoting the migration and metastasis of HCC cells. 
Furthermore, using a dual-luciferase assay, we showed in the present study that the mRNA encoding claudin 11 (CLDN11), which is an integral membrane protein and a component of tight junction strands, was a direct target of miR-99b and we further demonstrated that the expression of CLDN11 was regulated by miR-99b in HCC cell lines and in HCC tissues. These results indicated that overexpression of miR-99b promotes metastatic growth and the migration of HCC cells through inhibition of CLDN11 expression, thus providing a better understanding of the underlying mechanism of the role of miR-99b in the pathogenesis of HCC.

\section{Materials and methods}

Human tumor samples. A total of 104 pairs of HCC and adjacent non-tumor liver tissue (ANLT) samples were obtained from patients who underwent hepatectomy between January 2007 and December 2011 at Xiangya Hospital, Central South University in China. Sixteen cases of normal liver tissues were obtained from tissues distant from the liver hemangioma tissues. Tumor or normal liver tissues were snap-frozen immediately after surgery and stored in liquid nitrogen at $-80^{\circ} \mathrm{C}$. Histopathology was evaluated by pathologists at the Pathology Department of Xiangya Hospital. Patient informed consents were obtained from every patient before surgery. The study protocol was approved by the Ethics Committee of Central South University.

Cell lines. HCC cell lines (HepG2, HUH7, HCCLM3 and SMMC7721) and a normal liver cell line (L02) were obtained from the Central Experimental Laboratory of Xiangya Medical School in Central South University and cultured in Dulbecco's modified Eagle's medium (DMEM) supplemented with $10 \%$ fetal bovine serum (FBS) (both from Sigma-Aldrich, St. Louis, MO, USA), $1 \%$ penicillin/streptomycin $(50 \mathrm{U} / \mathrm{ml})$ and $1 \%$ L-glutamine $(2 \mathrm{mmol} / \mathrm{l}$ ) (both from Invitrogen, Basel, Switzerland). All cell lines were cultured at $37^{\circ} \mathrm{C}$ in humidified air with $5 \% \mathrm{CO}_{2}$.

Real-time PCR. Total RNA of HCC tissues and cultured cells was extracted using TRIzol (Beyotime Institute of Biotechnology, Beijin, China) according to the manufacturer's instructions. Reverse transcription was performed using the First Strand cDNA Synthesis ReverTra Ace kit (Toyobo, Tokyo, Japan). Real-time PCR was performed with the SYBR-Green PCR Master Mix (Roche Applied Science, Indianapolis, IN, USA) according to the manufacturer's instructions using the ABI 7300 Real-Time PCR System. U6 snRNA was measured as an internal control for miRNA and GAPDH was used for normalization for mRNA. The primers for CLDN11 were: forward primer 5'-ACCATCGTGAGCTTTGGCTA-3' and reverse primer 5'-GCTAGAGCCCGCAGTGTAGT-3'.

Transfection and luciferase assay. The 293T cell line was seeded in 24-well plates and infected with miR-99b overexpression lentivirus. pGL3 vector with mutant (Mut) CLDN11-3UTR' or wild-type (Wt) CLDN11-3'UTR as well as $2 \mathrm{ng} /$ well of plasmid pRL-TK were cotransfected using Lipofectamine LTX (Invitrogen, Carlsbad, CA, USA) according to the manufacturer's instructions. Three days later, the cell lines were extracted and the relative luciferase activity assay was performed using a Dual-Luciferase Reporter Assay system (Promega, Madison, WI, USA).

Lentivirus. The miR-99b overexpression lentivirus and the miR-99b inhibition lentivirus as well as their control lentiviruses were purchased from GenePharma Biotechnology Corp. (Shanghai, China). The conservation and usage of the lentiviruses were performed according to the manufacturer's instructions. GFP in the HCC cells was used to verify the infection efficiency of the cells.

Matrigel invasion assays. Cell motility and migratory abilities were assessed using a Transwell plate with Matrigel (Corning Life Sciences, Bedford, MA, USA). Matrigel invasion assays were performed as previously described. Cells $\left(2 \times 10^{4}\right)$ were suspended in serum-free culture medium and seeded into the upper chamber. Culture medium supplemented with 10\% FBS was added to the lower chamber. Cells were incubated in a $\mathrm{CO}_{2}$ incubator at $37^{\circ} \mathrm{C}$ for $24 \mathrm{~h}$. Cells in the upper chamber and Matrigel were removed. Cells that migrated to the underside of the membrane were fixed and stained with $0.1 \%$ crystal violet. Cells that migrated through the membrane pores to the lower surface of the membrane were counted in 10 microscopic fields. Each experiment was performed in replicate inserts.

Western blot analysis. Total cellular lysates were obtained by lysing cells in RIPA buffer containing proteinase and phosphatase inhibitors. Proteins were extracted from the total cellular lysates. Extracts (5-30 $\mu \mathrm{g})$ were separated on $12 \%$ polyacrylamide gels and transferred onto PVDF membranes. Western blot analyses were performed as previously described (16). Anti-CLDN11 antibody (Santa Cruz) and $\beta$-actin antibody (Sigma) were used in western blot analysis according to the manufacturer's instructions.

Immunohistochemistry (IHC) analysis. The paraffin-embedded tissue samples from postoperative patients were cut into $5-\mu \mathrm{m}$ sections. Then the samples were deparaffinized in xylene and rehydrated using a series of graded alcohols. Slides were blocked with $10 \%$ goat serum before incubating with anti-CLDN11 antibody (dilution 1:50) (Santa Cruz). The samples were incubated overnight with a primary antibody, and subsequent secondary antibody followed by 3,3'-diaminobenzidine (DAB).

Cell migration assay. Cell motility and migratory abilities were assessed by Transwell assay (Corning Life Sciences). Cell migration assays were performed as previously described. Cells $\left(2 \times 10^{4}\right)$ were suspended in serum-free culture medium and seeded into the upper chamber. Culture medium supplemented with $10 \%$ FBS was added to the lower chamber. Cells were incubated in a $\mathrm{CO}_{2}$ incubator at $37^{\circ} \mathrm{C}$ for $24 \mathrm{~h}$. Cells that migrated to the underside of the membrane were fixed and stained with $0.1 \%$ crystal violet. Cells that migrated through the membrane pores to the lower surface of the membrane were counted in 10 microscopic fields. Each experiment was performed in replicate inserts.

Statistical analysis. Statistical analysis was performed using SPSS version 16.0 (SPSS, Inc., Chicago, IL, USA). Values are expressed as the mean \pm SD. The difference between groups 
was analyzed using an independent Student's t-test when comparing only two groups or one-way ANOVA analysis of variance when comparing more than two groups. Fisher's exact test was adopted for statistical analysis of categorical data. Spearman correlation test was used for analyzing the correlations between the miR-99b expression level and the clinical and pathological variables. Kaplan-Meier's method was used to construct survival curves. Equivalences of the survival curves were tested by log-rank statistics. The independent risk factors for OS and DFS were identified by Cox proportional hazard regression model. A two-tailed $\mathrm{P}<0.05$ was considered to a statistically significant result.

\section{Results}

miR-99b is expressed at elevated levels in HCC cell lines and in tissues of patients with HCC. We collected 104 pairs of HCC tissues and adult normal liver tissue (ANLT) to assess miR-99b expression. miR-99b was expressed at $>2$-fold higher levels in $75(72.1 \%)$ HCC tissues compared with the level in the ANLT samples (Fig. 1A). The median level of miR-99b expression in the HCC tissues was significantly higher (3.8-fold) compared with that of the ANLT samples $(5.53 \pm 0.80$ vs. $1.44 \pm 0.24$, $\mathrm{P}<0.001)$ or $\sim 8.0$-fold higher compared with that in the normal liver tissues $(5.53 \pm 0.80$ vs. $0.69 \pm 0.15, \mathrm{P}=0.002)$ (Fig. 1B). However, there was no significant difference between miR-99b levels in the ANLT and normal liver tissues (1.44 \pm 0.24 vs. $0.69 \pm 0.15, \mathrm{P}=0.632)$. We determined miR-99b expression levels in four HCC cell lines (HepG2, Huh7, HCCLM3 and SMMC7721) and a normal liver cell line (LO2) that served as a control. miR-99b was expressed in the four HCC lines at levels significantly higher compared with the LO2 cells (5.34-, 4.28-, 7.88- and 2.15-fold, respectively) (Fig. 1C).

High levels of miR-99b expression predict poor prognosis of patients with HCC. We determined the levels of miR-99b expression in tissues acquired from 104 patients with HCC and classified the patients into a high expression (greater than the median) and a low expression (less than the median) group, and analyzed the group clinicopathological characteristics and clinical courses. We acquired data for gender, age, tumor size, tumor number, $\alpha$-fetoprotein (AFP), hepatitis B virus (HBV) infection, liver cirrhosis, capsule formation, Edmondson stage, microvascular invasion and TNM stage, and found a significant association with capsule formation $(\mathrm{P}=0.030)$ and microvascular invasion $(\mathrm{P}=0.017)$ (Table I).

To assess the feasibility of miR-99b as a marker for postoperative prognosis, we performed univariate and multivariate analyses of OS (Table II) and DFS (Table III). Univariate analysis revealed that the tumor size $(\mathrm{P}=0.006)$, liver cirrhosis $(\mathrm{P}=0.010)$, microvascular invasion $(\mathrm{P}=0.001)$, TNM stage $(\mathrm{P}=0.002)$ and the miR-99b expression $(\mathrm{P}<0.001)$ were significantly associated with the OS of patients with HCC and that liver cirrhosis $(\mathrm{P}=0.014)$, microvascular invasion $(\mathrm{P}=0.004)$, TNM stage $(\mathrm{P}=0.003)$ and miR-99b expression $(\mathrm{P}=0.002)$ were significantly associated with DFS.

Multivariate analysis revealed that tumor size $(\mathrm{P}=0.023)$, liver cirrhosis $(\mathrm{P}=0.002)$, microvascular invasion $(\mathrm{P}=0.020)$ and miR-99b expression $(\mathrm{P}<0.001)$ were independent prognostic indicators of OS and that miR-99b expression $(\mathrm{P}=0.025)$
Table I. Correlation between miR-99b expression and clinicopathological features of the HCC patients.

\begin{tabular}{|c|c|c|c|c|c|}
\hline \multirow[b]{2}{*}{ Parameters } & \multirow[b]{2}{*}{ Cases } & \multicolumn{2}{|c|}{$\begin{array}{c}\text { miR-99b } \\
\text { expression }\end{array}$} & \multirow[b]{2}{*}{$\chi^{2}$} & \multirow[b]{2}{*}{ P-value } \\
\hline & & Low & High & & \\
\hline \multicolumn{6}{|l|}{ Gender } \\
\hline Female & 13 & 7 & 6 & & \\
\hline Male & 91 & 45 & 46 & 0.088 & 0.767 \\
\hline \multicolumn{6}{|l|}{ Age (years) } \\
\hline$<60$ & 84 & 43 & 41 & & \\
\hline$>60$ & 20 & 9 & 11 & 0.248 & 0.619 \\
\hline \multicolumn{6}{|c|}{ Tumor size $(\mathrm{cm})$} \\
\hline$<5$ & 18 & 10 & 8 & & \\
\hline$\geq 5$ & 86 & 42 & 44 & 0.269 & 0.604 \\
\hline \multicolumn{6}{|l|}{ Tumor no. } \\
\hline Single & 56 & 30 & 26 & & \\
\hline Multiple & 48 & 22 & 26 & 0.619 & 0.431 \\
\hline \multicolumn{6}{|l|}{$\mathrm{AFP}(\mathrm{ng} / \mathrm{ml})$} \\
\hline$<20$ & 39 & 18 & 21 & & \\
\hline$\geq 20$ & 65 & 34 & 31 & 0.369 & 0.543 \\
\hline \multicolumn{6}{|c|}{ HBV infection } \\
\hline Negative & 10 & 6 & 4 & & \\
\hline Positive & 92 & 46 & 46 & 1.390 & 0.499 \\
\hline \multicolumn{6}{|c|}{ Liver cirrhosis } \\
\hline Absence & 22 & 14 & 8 & & \\
\hline Presence & 82 & 38 & 44 & 2.075 & 0.150 \\
\hline \multicolumn{6}{|c|}{ Capsular formation } \\
\hline Presence & 47 & 29 & 18 & & \\
\hline Absence & 57 & 23 & 34 & 4.697 & 0.030 \\
\hline \multicolumn{6}{|c|}{ Edmondson stage } \\
\hline I-II & 43 & 20 & 23 & & \\
\hline III-IV & 61 & 32 & 29 & 0.357 & 0.691 \\
\hline \multicolumn{6}{|c|}{ Microvascular invasion } \\
\hline No & 59 & 36 & 23 & & \\
\hline Yes & 45 & 16 & 29 & 6.620 & 0.017 \\
\hline \multicolumn{6}{|l|}{ TNM stage } \\
\hline I & 38 & 22 & 16 & & \\
\hline II & 25 & 12 & 13 & & \\
\hline III & 41 & 18 & 23 & 1.597 & 0.450 \\
\hline
\end{tabular}

HCC, hepatocellular carcinoma; AFP, $\alpha$-fetoprotein; HBV, hepatitis $\mathrm{B}$ virus; TNM, tumor node metastasis. Bold print indicates a significant difference.

and liver cirrhosis $(\mathrm{P}=0.018)$ were independent prognostic indicators of DFS. When we performed Kaplan-Meier analysis, we found that OS and DFS were shorter for patients with HCC who expressed high levels of miR-99b (Fig. 1D and E). The 1-, 3- and 5-year OS values of patients in the high miR-99b expression group were 51.5, 24.2 and $12.1 \%$, respectively, and significantly lower compared with those of patients in the low 

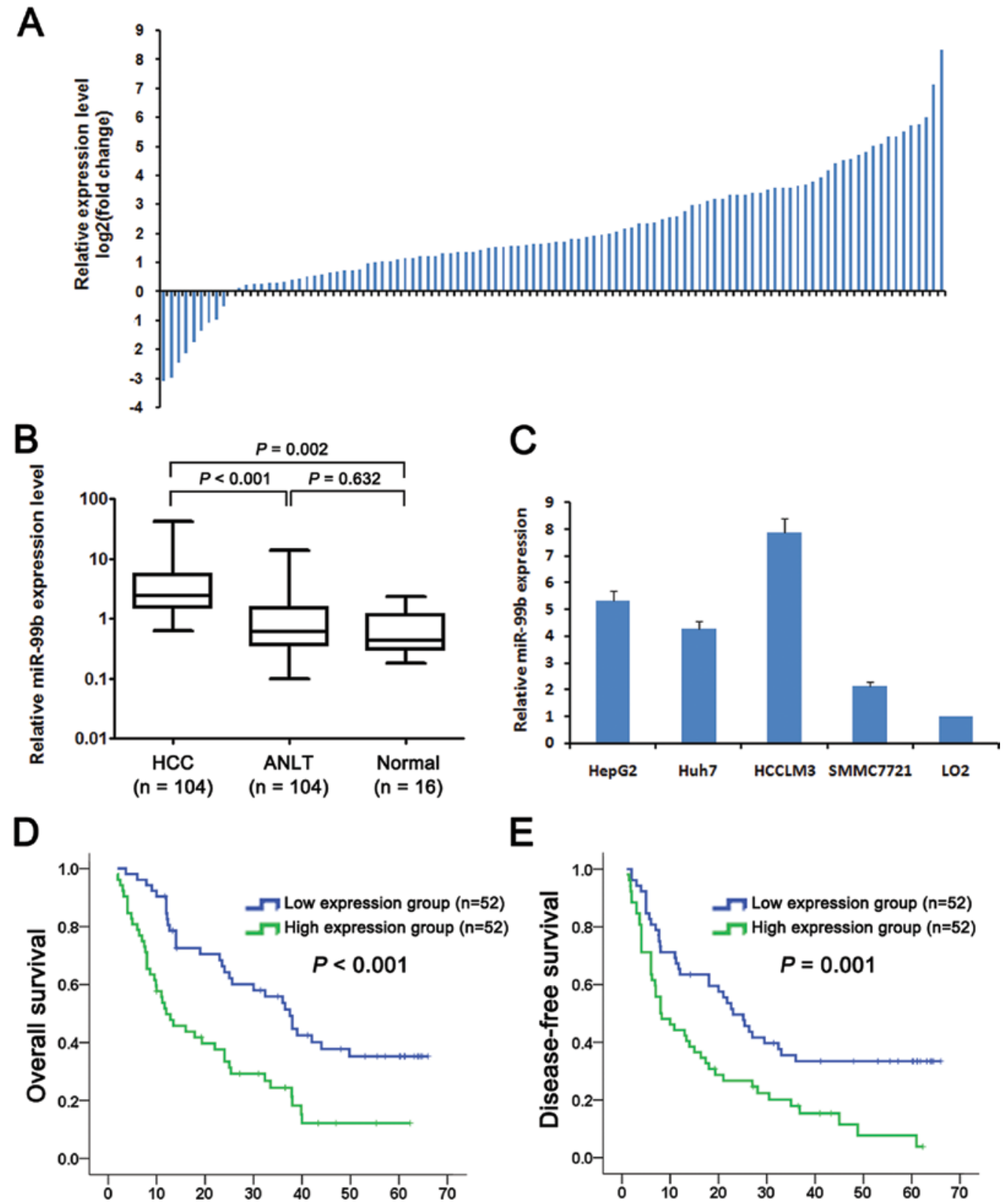

E

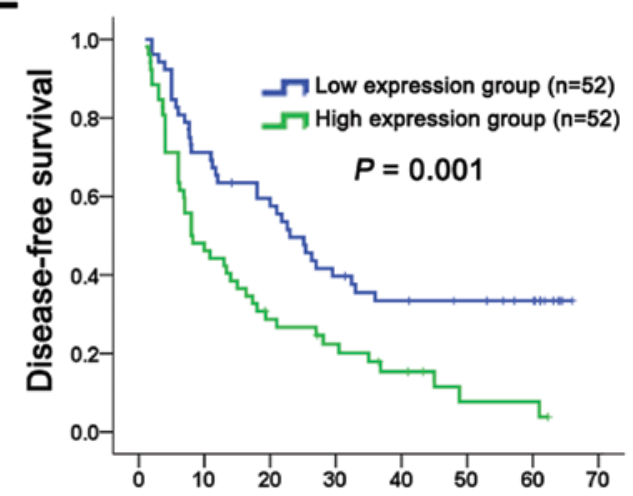

Figure 1. miR-99b is frequently upregulated in HCC and is related to the prognosis of HCC. (A) Expression of miR-99b in 104 pairs of HCC and corresponding ANLT. miR-99b expression was normalized to the corresponding levels of U6. Data were analyzed using a $\Delta \Delta C t$ approach. Fold-change was calculated as $2^{-\triangle \Delta C(\text { HCC/ANLT) }}$. (B) Relative miR-99b expression in HCC, ANLT and normal tissues. Boxes represent the median and interquartile ranges of the normalized threshold values. miR-99b expression levels were calculated by the $2^{-\Delta \mathrm{Ct}}$ method and normalized to U6 small nuclear RNA. (C) Relative miR-99b expression in four HCC cell lines including HepG2, Huh7, HCCLM3 and SMMC7721 and a normal liver cell line LO2. Based on the data of qRT-PCR, the patients were classified into a high expression group $(n=52)$ and a low expression group $(n=52)$. (D) The overall and (E) disease-free survival of the two groups were compared by Kaplan-Meier method. ANLT, adjacent non-tumorous liver tissues.

miR-99b expression group $(90.3,55.5$ and $34.7 \%$, respectively, $\mathrm{P}<0.001)$. Furthermore, the values for the 1-, 3- and 5-year DFS of the high miR-99b group were 44.2, 18.0 and $8.3 \%$, respectively, and significantly lower compared with those of the low miR-99b group $(65.4,35.5$ and $33.4 \%$, respectively; $\mathrm{P}=0.001)$.

miR-99b promotes the metastatic phenotype of HCC cell lines. The HCC HCCLM3 and SMMC7721 cell lines that expressed the highest and lowest levels of miR-99b, respectively, among the four cell lines tested, were infected with lentiviruses that expressed the antisense version of miR-99b or overexpressed
miR-99b as well as with the respective cognate negative control (NC). We isolated stably transduced cell lines of each infectant, designated HCCLM3 $3^{\text {anti-miR-99b }}$, SMMC7721 ${ }^{\text {miR-99b }}$, HCCLM3 $3^{\text {NC }}$ and SMMC $7721^{\mathrm{NC}}$. Real-time PCR analysis showed that miR-99b HCCLM3 $3^{\text {anti-miR-99b }}$ cells expressed miR-99b at a level $40 \%$ lower compared with that of the HCCLM3 $3^{\mathrm{NC}}$ cells (Fig. 2A, P<0.01). Furthermore, SMMC7721 $1^{\text {miR-99b }}$ cells expressed miR-99b at a level 3-fold higher compared with the SMMC $7721^{\text {NC }}$ cells (Fig. 2B, P<0.01).

Using wound healing and Matrigel invasion assays, we evaluated whether the levels of miR-99b expression in these cell lines imparted a metastatic phenotype. HCCLM3 $3^{\text {anti-miR-99b }}$ 
Table II. Univariate and multivariate analyses of overall survival by a Cox proportional hazards regression model.

\begin{tabular}{|c|c|c|c|c|c|}
\hline \multirow[b]{2}{*}{ Parameters } & \multirow[b]{2}{*}{ Case } & \multicolumn{2}{|c|}{ Univariate analysis } & \multicolumn{2}{|c|}{ Multivariate analysis } \\
\hline & & $\mathrm{HR}(95 \% \mathrm{CI})$ & P-value & HR $(95 \% \mathrm{CI})$ & P-value \\
\hline \multicolumn{6}{|l|}{ Gender } \\
\hline Female & 13 & 1 & & & \\
\hline Male & 91 & $1.079(0.537-2.169)$ & 0.831 & & NA \\
\hline \multicolumn{6}{|l|}{ Age (years) } \\
\hline$<60$ & 84 & 1 & & & \\
\hline$>60$ & 20 & $1.023(0.571-1.832)$ & 0.940 & & NA \\
\hline \multicolumn{6}{|c|}{ Tumor size $(\mathrm{cm})$} \\
\hline$<5$ & 18 & 1 & & 1 & \\
\hline$\geq 5$ & 86 & $3.201(1.385-7.397)$ & 0.006 & $2.550(1.140-5.704)$ & 0.023 \\
\hline \multicolumn{6}{|l|}{ Tumor no. } \\
\hline Single & 56 & 1 & & & \\
\hline Multiple & 48 & $1.563(0.986-2.476)$ & 0.057 & & NA \\
\hline \multicolumn{6}{|l|}{$\operatorname{AFP}(\mathrm{ng} / \mathrm{ml})$} \\
\hline$<20$ & 39 & 1 & & & \\
\hline$\geq 20$ & 65 & $1.264(0.779-2.052)$ & 0.343 & & NA \\
\hline \multicolumn{6}{|c|}{ HBV infection } \\
\hline Negative & 10 & 1 & & & \\
\hline Positive & 92 & $1.714(0.736-3.990)$ & 0.211 & & NA \\
\hline \multicolumn{6}{|c|}{ Liver cirrhosis } \\
\hline Absence & 22 & 1 & & 1 & \\
\hline Presence & 82 & $2.297(1.225-4.307)$ & 0.010 & $2.793(1.442-5.413)$ & 0.002 \\
\hline \multicolumn{6}{|c|}{ Capsular formation } \\
\hline Presence & 47 & 1 & & & \\
\hline Absence & 57 & $1.433(0.896-2.292)$ & 0.133 & & NA \\
\hline \multicolumn{6}{|c|}{ Edmondson stage } \\
\hline I-II & 43 & 1 & & & \\
\hline III-IV & 61 & $0.773(0.478-1.226)$ & 0.274 & & NA \\
\hline \multicolumn{6}{|c|}{ Microvascular invasion } \\
\hline No & 59 & 1 & & 1 & \\
\hline Yes & 45 & $2.138(1.346-3.394)$ & 0.001 & $1.899(1.106-3.258)$ & 0.020 \\
\hline \multicolumn{6}{|l|}{ TNM stage } \\
\hline I-II & 63 & 1 & & 1 & \\
\hline III & 41 & $1.526(1.167-1.994)$ & 0.002 & $1.244(0.907-1.706)$ & 0.175 \\
\hline \multicolumn{6}{|c|}{ miR-99b expression } \\
\hline Low & 52 & 1 & & 1 & \\
\hline High & 52 & $2.408(1.501-3.864)$ & $<0.001$ & 2.447 (1.506-3.976) & $<0.001$ \\
\hline
\end{tabular}

cells promoted wound healing that was slower compared with the HCCLM3 ${ }^{\mathrm{NC}}$ cells. Similarly, the SMMC7721 ${ }^{\text {miR-99b }}$ cells promoted more rapid wound healing compared with the SMMC7721 ${ }^{\mathrm{NC}}$ cells (Fig. 2D). The Matrigel assays revealed that the HCCLM3 ${ }^{\text {anti-miR-99b }}$ cells migrated more slowly compared with the HCCLM3 ${ }^{\mathrm{NC}}$ cells (Fig. 2E), while the SMMC7721 ${ }^{\text {miR-99b }}$ migrated faster compared with the
SMMC7721 ${ }^{\mathrm{NC}}$ cells (Fig. 2F). These data indicate that cells with elevated levels of miR-99b exhibited phenotypic characteristics of metastatic cells.

miR-99b directly inhibits CLDN11 expression. To determine whether miR-99b expression contributes to the metastatic phenotype of HCC cells, we searched the 
A
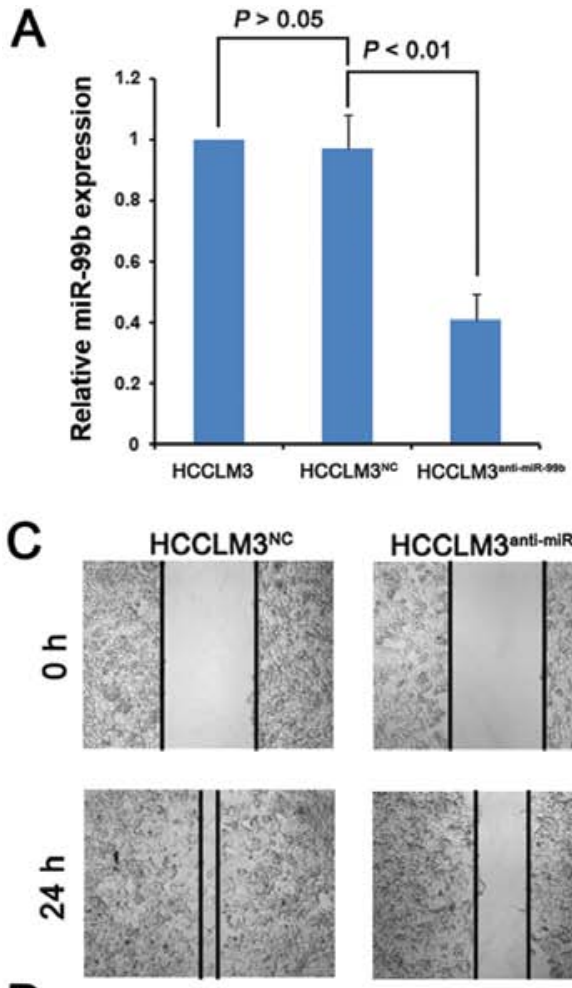

D
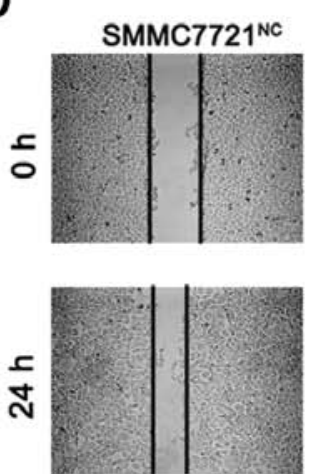

B

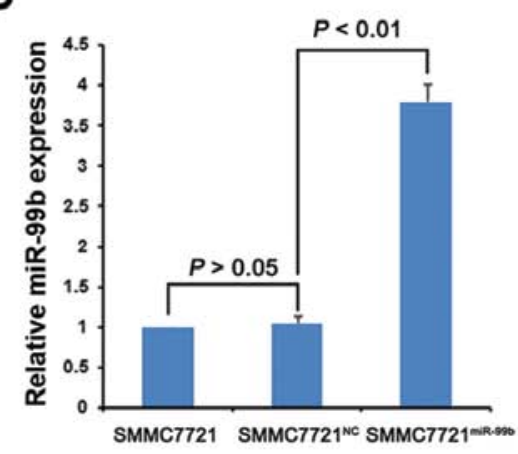

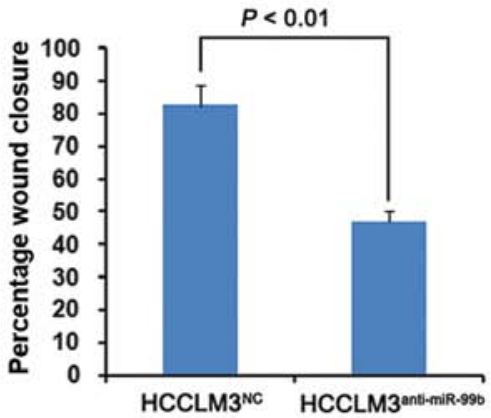
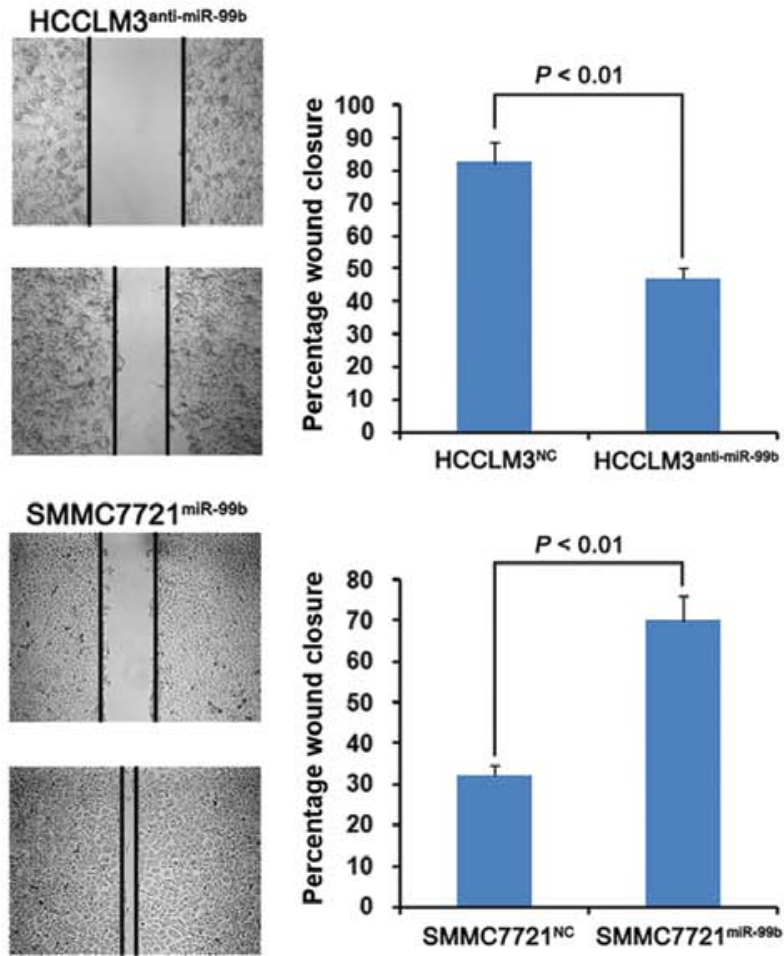

E
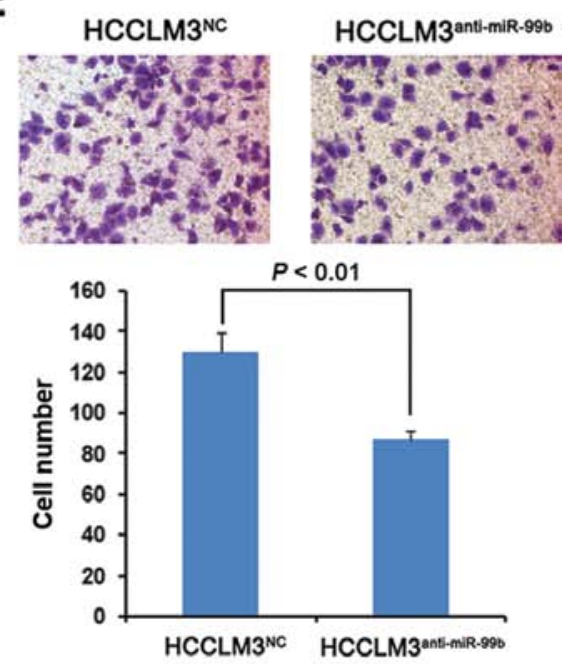

F
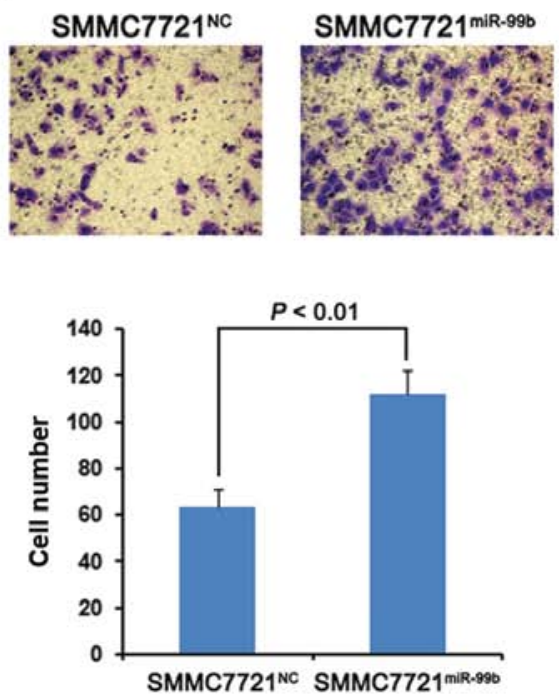

Figure 2. miR-99b promotes HCC cell migration and invasion in vitro. (A) Relative miR-99b expression in HCCLM3 as well as HCCLM3 cells infected with anti-miR-99b lentivirus or negative control (NC) lentivirus. The miR-99b expression in untreated HCCLM3 was set as 1. (B) Relative miR-99b expression in SMMC7721 as well as SMMC7721 cells infected with the miR-99b expression lentivirus or negative control (NC) lentivirus. The miR-99b expression in untreated SMMC7721 was set as 1 . The wound healing assays were employed to determine the migratory ability of the (C) HCCLM3 ${ }^{\text {NC }}$ and HCCLM3 ${ }^{\text {anti-mir-99b }}$ cells as well as the (D) SMMC7721 ${ }^{\mathrm{NC}}$ and SMMC7721 $1^{\mathrm{mir}-99 \mathrm{~b}}$ cells. The histogram on the right shows the percentage of wound closure for each HCC cell line. (E and F) Transwell assays with Matrigel were used to compare the invasion abilities of the HCC cells infected with the anti-miR-99b or miR-99b expression lentivirus and their corresponding control lentivirus.

TargetScan (www.targetscan.org), PicTar (www.pictar.org) and miRanda (www.microrna.org) databases for genes that are potential targets of miR-99b. We focused on CLDN11, since it was predicted as a target by our analysis of each database. To determine whether the 3'UTR of CLDN11 mRNA binds miR-99b, we mutated five bases of the CLDN11-3'UTR (Fig. 3A). The Wt and Mut sequences were each cloned into the luciferase reporter vector pGL3 and each was used with the control vector pRL-TK to cotransfect 293T cells. The result of the dual-luciferase assay showed that miR-99b overexpression significantly inhibited the luciferase activity of Wt 3'UTR of CLDN11 mRNA but not that of Mut 3'-UTR of CLDN11 mRNA (Fig. 3B). Furthermore, there was a significant inverse association between the expression of miR-99b and CLDN11 mRNA in the 104 matched pairs of
HCC specimens $\left(\mathrm{R}^{2}=0.302, \mathrm{P}=0.001\right.$; Fig. $\left.3 \mathrm{C}\right)$. To determine the functional significance of $C L D N 11$ mRNA expression, we performed western blot analyses of the levels of CLDN11 in the HCCLM3 and SMMC7721 cell lines infected with the lentivirus expression vectors as previously described, and found that knockdown of miR-99b expression significantly increased CLDN11 levels in the HCCLM3 cells. In contrast, CLDN11 levels were decreased in the infected cells that expressed miR-99b (Fig. 3D). Thus, these data indicate that miR-99b negatively regulates the expression of CLDN11 mRNA by directly targeting the 3'-UTR.

To determine whether miR-99b influences CLDN11 expression in human HCC tissues, we used immunohistochemistry to analyze three samples each with high or low miR-99b expression and found that CLDN11 was expressed 
Table III. Univariate and multivariate analyses of disease-free survival by a Cox proportional hazards regression model.

\begin{tabular}{|c|c|c|c|c|c|}
\hline \multirow[b]{2}{*}{ Parameters } & \multirow[b]{2}{*}{ Case } & \multicolumn{2}{|c|}{ Univariate analysis } & \multicolumn{2}{|c|}{ Multivariate analysis } \\
\hline & & HR (95\% CI) & P-value & $\mathrm{HR}(95 \% \mathrm{CI})$ & P-value \\
\hline \multicolumn{6}{|l|}{ Gender } \\
\hline Female & 13 & 1 & & & \\
\hline Male & 91 & $0.969(0.484-1.941)$ & 0.930 & & NA \\
\hline \multicolumn{6}{|l|}{ Age (years) } \\
\hline$<60$ & 84 & 1 & & & \\
\hline$>60$ & 20 & $1.002(0.984-1.020)$ & 0.816 & & NA \\
\hline \multicolumn{6}{|c|}{ Tumor size $(\mathrm{cm})$} \\
\hline$<5$ & 18 & 1 & & & \\
\hline$\geq 5$ & 86 & $1.836(0.970-3.478)$ & 0.062 & & NA \\
\hline \multicolumn{6}{|l|}{ Tumor no. } \\
\hline Single & 56 & 1 & & & \\
\hline Multiple & 48 & $1.538(0.990-2.390)$ & 0.056 & & NA \\
\hline \multicolumn{6}{|c|}{$\operatorname{AFP}(\mathrm{ng} / \mathrm{ml})$} \\
\hline$<20$ & 39 & 1 & & & \\
\hline$\geq 20$ & 65 & $1.247(0.787-1.976)$ & 0.348 & & NA \\
\hline \multicolumn{6}{|c|}{ HBV infection } \\
\hline Negative & 10 & 1 & & & \\
\hline Positive & 92 & $1.680(0.756-3.773)$ & 0.203 & & NA \\
\hline \multicolumn{6}{|c|}{ Liver cirrhosis } \\
\hline Absence & 22 & 1 & & 1 & \\
\hline Presence & 82 & $2.120(1.164-3.858)$ & 0.014 & $2.091(1.133-3.859)$ & 0.018 \\
\hline \multicolumn{6}{|c|}{ Capsular formation } \\
\hline Presence & 47 & 1 & & & \\
\hline Absence & 57 & $1.307(0.837-2.041)$ & 0.239 & & NA \\
\hline \multicolumn{6}{|c|}{ Edmondson stage } \\
\hline I-II & 43 & 1 & & & \\
\hline III-IV & 61 & $0.712(0.456-1.114)$ & 0.137 & & NA \\
\hline \multicolumn{6}{|c|}{ Microvascular invasion } \\
\hline No & 59 & 1 & & 1 & \\
\hline Yes & 45 & $1.919(1.233-2.986)$ & 0.004 & $1.522(0.923-2.509)$ & 0.099 \\
\hline \multicolumn{6}{|l|}{ TNM stage } \\
\hline I-II & 63 & 1 & & 1 & \\
\hline III & 41 & $1.469(1.135-1.902)$ & 0.003 & $1.326(0.980-1.794)$ & 0.067 \\
\hline \multicolumn{6}{|c|}{ miR-99b expression } \\
\hline Low & 52 & 1 & & 1 & \\
\hline High & 52 & $2.049(1.308-3.208)$ & 0.002 & $1.694(1.068-2.685)$ & 0.025 \\
\hline
\end{tabular}

at significantly lower levels in the tissues with high miR-99b expression, consistent with the cell line data (Fig. 3E).

\section{Discussion}

In the present study, we showed that the median level of miR-99b expression in HCC tissues was significantly higher when compared with that of ANLT or normal liver tissues. Furthermore, miR-99b was expressed at significantly higher levels compared with the controls in $72.1 \%$ (75/104) of HCC tissues and in four HCC cell lines. Moreover, increased miR-99b expression was significantly associated with capsule formation and microvascular invasion, which indicated poor prognosis. We further showed that miR-99b expression levels 

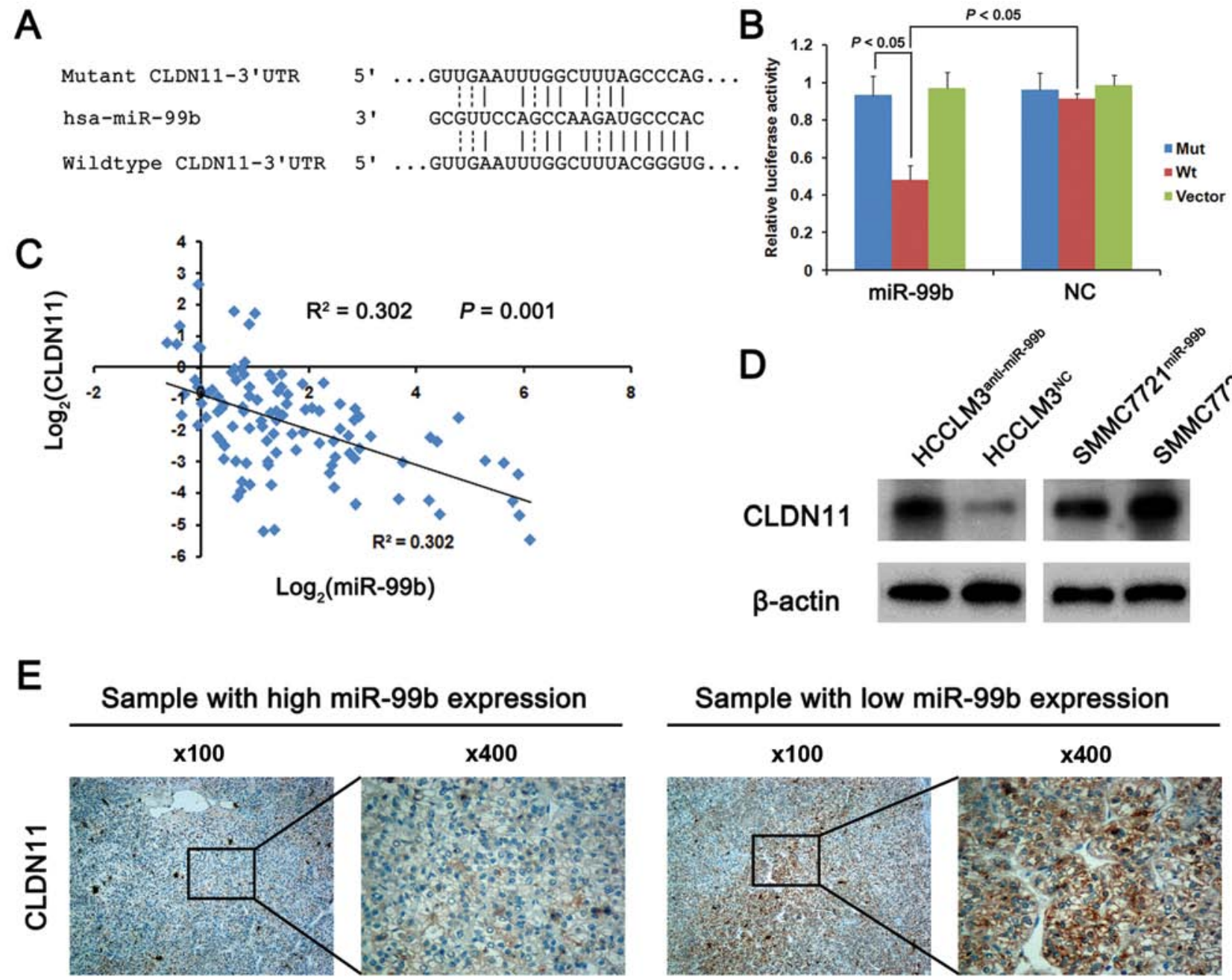

Figure 3. CLDN11 is the direct target of miR-99b. (A) Putative miR-99b binding sequences in the 3'UTR of CLDN11 mRNA. The mutant miR-99b binding sites were generated in the complementary site for the seed region of miR-99b. (B) Relative luciferase assay comparing the 293T cells cotransfected with pGL3-wild-type CLDN11-3'UTR (Wt) or pGL3-mutant CLDN11-3'UTR (Mut) or untreated pGL3 vector (vector) and a Renilla luciferase vector. The firefly luciferase activity was normalized to the Renilla luciferase activity. (C) Inverse association between miR-99b and CLDN11 expression at mRNA levels in $104 \mathrm{HCC}$ specimens. (D) Western blot analysis of CLDN11 expression in HCC cells infected with the miR-99b expression lentivirus or anti-miR-99b lentivirus or NC. (E) Analysis of CLDN11 expressions in HCC tissues by immunohistochemistry. Representative images showed the expression of CLDN11 in HCC tissues with high miR-99b expression and in HCC tissues with relative low-miR-99b expression. 3'UTR, 3' untranslated region.

were inversely related to the OS and DFS of patients, and served as an independent risk factor for OS and DFS, indicating that miR-99b is a potential biomarker for HCC recurrence.

CLDN11 is a crucial component of tight junction strands $(17,18)$. The tight junction is often altered in human carcinomas, and the loss of the tight junction leads to cancer progression $(19,20)$. Moreover, the tight junction plays a number of diverse roles in tumorigenesis, including cell signaling, cytoskeletal regulation, cell growth, cell motility, differentiation and maintenance of cell polarity (21-23). Agarwal et al reported that silencing of CLDN11 expression contributes to gastric carcinogenesis by increasing cell motility and invasiveness (24). Moreover, the loss of CLDN11 is a putative indicator of recurrence and more aggressive behavior of meningiomas (25). Consistent with these findings, enforced expression of $C L D N 11$ decreased the invasiveness of bladder cancer cell lines (26), indicating its role in preventing cancer progression and its potential as a therapeutic target for inhibiting metastatic growth.
miRNAs contribute to homeostasis and pathologies via inhibiting target genes at the posttranscriptional level (27). In the present study, we investigated the mechanism by which miR-99b promotes the progression of HCC. Using bioinformatics, we predicted that CLDN11 mRNA is an miR-99b target. The results of dual-luciferase reporter assays support this conclusion. Moreover, overexpression of miR-99b significantly inhibited CLDN11 expression and enhanced the metastatic phenotype of the HCC cell lines, and knockdown of miR-99b expression increased that of CLDN11 and attenuated the metastatic phenotype of the HCC cell lines. In agreement with a study of bladder cancer cells (26), CLDN11 mRNA expression was downregulated in $90.4 \%(94 / 104)$ of HCC tissues studied in the present study, suggesting the contribution to HCC pathogenesis. Furthermore, we showed in the present study that CLDN11 mRNA was expressed at low levels in HCC tissues with relatively high levels of miR-99b expression. Conversely, CLDN11 mRNA was expressed at high levels in HCC tissues with low levels of miR-99b expression. Collectively, these data 
indicate that miR-99b inhibits $C L D N 11$ expression at the posttranscriptional level and contributes to HCC metastasis.

Epithelial cells adhere through intercellular adhesion complexes such as the tight junction. Mesenchymal cells are non-polarized, lack intercellular junctions and migrate individually throughout the extracellular matrix (28). The tight junction maintains cell polarity and influences cell motility (29). Tight junction-associated proteins promote the EMT through the regulation of tight junctions in human breast cancer cell lines (30). In the present study, we showed that miR-99b promoted the metastatic phenotype of HCC cell lines through the tight junction-associated protein CLDN11. Therefore, we suggested that miR-99b inhibits CLDN11 expression and reduces the abundance of tight junctions to promote the EMT of HCC cells, leading to increased metastasis of HCC. Further studies are required to confirm these speculations.

In conclusion, we demonstrated that miR-99b is expressed at high levels in HCC tissues compared with ANLT. Upregulation of miR-99b expression was positively correlated with poor clinicopathological characteristics of the patients with HCC and was associated with poor OS and DFS of postoperative patients. Our data indicated that miR-99b functions as an oncogene that promotes the metastasis of HCC via inhibiting CLDN11 expression. Therefore, miR-99b serves as a diagnostic marker as well as a therapeutic target for HCC.

\section{References}

1. Yang JD and Roberts LR: Hepatocellular carcinoma: A global view. Nat Rev Gastroenterol Hepatol 7: 448-458, 2010.

2. Venook AP, Papandreou C, Furuse J and de Guevara LL: The incidence and epidemiology of hepatocellular carcinoma: A global and regional perspective. Oncologist 15 (Suppl 4): S5-S13, 2010.

3. Jemal A, Bray F, Center MM, Ferlay J, Ward E and Forman D: Global cancer statistics. CA Cancer J Clin 61: 69-90, 2011.

4. Zhong JH, Ke Y, Gong WF, Xiang BD, Ma L, Ye XP, Peng T, Xie GS and Li LQ: Hepatic resection associated with good survival for selected patients with intermediate and advancedstage hepatocellular carcinoma. Ann Surg 260: 329-340, 2014.

5. Pang RW, Joh JW, Johnson PJ, Monden M, Pawlik TM and Poon RT: Biology of hepatocellular carcinoma. Ann Surg Oncol 15: 962-971,2008.

6. Bartel DP: MicroRNAs: Target recognition and regulatory functions. Cell 136: 215-233, 2009.

7. Bartel DP: MicroRNAs: Genomics, biogenesis, mechanism, and function. Cell 116: 281-297, 2004.

8. Kalluri R and Weinberg RA: The basics of epithelial-mesenchymal transition. J Clin Invest 119: 1420-1428, 2009.

9. Valastyan S and Weinberg RA: Tumor metastasis: Molecular insights and evolving paradigms. Cell 147: 275-292, 2011.

10. Yuan JH, Yang F, Wang F, Ma JZ, Guo YJ, Tao QF, Liu F, Pan W, Wang TT, Zhou CC, et al: A long noncoding RNA activated by TGF- $\beta$ promotes the invasion-metastasis cascade in hepatocellular carcinoma. Cancer Cell 25: 666-681, 2014.

11. Turcatel G, Rubin N, El-Hashash A and Warburton D: miR-99a and miR-99b modulate TGF- $\beta$ induced epithelial to mesenchymal plasticity in normal murine mammary gland cells. PLoS One 7: e31032, 2012.

12. Huang JJ, Yu J, Li JY, Liu YT and Zhong RQ: Circulating microRNA expression is associated with genetic subtype and survival of multiple myeloma. Med Oncol 29: 2402-2408, 2012.
13. Lionetti M, Biasiolo M, Agnelli L, Todoerti K, Mosca L, Fabris S, Sales G, Deliliers GL, Bicciato S, Lombardi L, et al: Identification of microRNA expression patterns and definition of a microRNA/mRNA regulatory network in distinct molecular groups of multiple myeloma. Blood 114: e20-e26, 2009.

14. Liu SG, Qin XG, Zhao BS, Qi B, Yao WJ, Wang TY, Li HC and Wu XN: Differential expression of miRNAs in esophageal cancer tissue. Oncol Lett 5: 1639-1642, 2013.

15. Feber A, Xi L, Pennathur A, Gooding WE, Bandla S, Wu M, Luketich JD, Godfrey TE and Litle VR: MicroRNA prognostic signature for nodal metastases and survival in esophageal adenocarcinoma. Ann Thorac Surg 91: 1523-1530, 2011.

16. Mikhaylova O, Stratton Y, Hall D, Kellner E, Ehmer B, Drew AF, Gallo CA, Plas DR, Biesiada J, Meller J, et al: VHL-regulated miR-204 suppresses tumor growth through inhibition of LC3Bmediated autophagy in renal clear cell carcinoma. Cancer Cell 21: 532-546, 2012.

17. Furuse M, Fujita K, Hiiragi T, Fujimoto K and Tsukita S: Claudin-1 and -2: Novel integral membrane proteins localizing at tight junctions with no sequence similarity to occludin. J Cell Biol 141: 1539-1550, 1998.

18. Morita K, Sasaki H, Fujimoto K, Furuse M and Tsukita S: Claudin-11/OSP-based tight junctions of myelin sheaths in brain and Sertoli cells in testis. J Cell Biol 145: 579-588, 1999.

19. Zhou W, Fong MY, Min Y, Somlo G, Liu L, Palomares MR, Yu Y, Chow A, O'Connor ST, Chin AR, et al: Cancer-secreted miR-105 destroys vascular endothelial barriers to promote metastasis. Cancer Cell 25: 501-515, 2014.

20. Yao Y, Gu X, Liu H, Wu G, Yuan D, Yang X and Song Y: Metadherin regulates proliferation and metastasis via actin cytoskeletal remodelling in non-small cell lung cancer. Br J Cancer 111: 355-364, 2014.

21. Alshbool FZ and Mohan S: Emerging multifunctional roles of Claudin tight junction proteins in bone. Endocrinology 155: 2363-2376, 2014 .

22. Garrido-Urbani S, Bradfield PF and Imhof BA: Tight junction dynamics: The role of junctional adhesion molecules (JAMs). Cell Tissue Res 355: 701-715, 2014.

23. Shang X, Lin X, Alvarez E, Manorek G and Howell SB: Tight junction proteins claudin- 3 and claudin- 4 control tumor growth and metastases. Neoplasia 14: 974-985, 2012.

24. Agarwal R, Mori Y, Cheng Y, Jin Z, Olaru AV, Hamilton JP, David S, Selaru FM, Yang J, Abraham JM, et al: Silencing of claudin-11 is associated with increased invasiveness of gastric cancer cells. PLoS One 4: e8002, 2009.

25. Soini Y, Rauramaa T, Alafuzoff I, Sandell PJ and Kärjä V: Claudins 1,11 and twist in meningiomas. Histopathology 56: 821-824, 2010

26. Awsare NS, Martin TA, Haynes MD, Matthews PN and Jiang WG: Claudin-11 decreases the invasiveness of bladder cancer cells. Oncol Rep 25: 1503-1509, 2011.

27. Giordano $S$ and Columbano A: MicroRNAs: New tools for diagnosis, prognosis, and therapy in hepatocellular carcinoma? Hepatology 57: 840-847, 2013.

28. Acloque H, Adams MS, Fishwick K, Bronner-Fraser M and Nieto MA: Epithelial-mesenchymal transitions: The importance of changing cell state in development and disease. J Clin Invest 119: 1438-1449, 2009.

29. Artus C, Glacial F, Ganeshamoorthy K, Ziegler N, Godet M, Guilbert T, Liebner S and Couraud PO: The Wnt/planar cell polarity signaling pathway contributes to the integrity of tight junctions in brain endothelial cells. J Cereb Blood Flow Metab 34: 433-440, 2014.

30. Zhao JL, Liang SQ, Fu W, Zhu BK, Li SZ, Han H and Qin HY: The LIM domain protein FHL1C interacts with tight junction protein ZO-1 contributing to the epithelial-mesenchymal transition (EMT) of a breast adenocarcinoma cell line. Gene 542: 182-189, 2014. 